\title{
O SUPREMO TRIBUNAL FEDERAL E A CIDADANIA À LUZ DA INFLUÊNCIA COMUNITARISTA
}

\author{
Julia Maurmann Ximenes
}

\section{RESUMO}

A CONSTITUição de 1988 atribuiu aO Supremo um DESENHO INSTITUCIONAL QUE REFLETE UMA VALORIZACÃO DO TEXTO CONSTITUCIONAL E UMA TENTATIVA DE APROXIMACCÃO DO EXERCÍCIO DA CIDADANIA NA LINHA DE UMA DEMOCRACIA PARTICIPATIVA, À LUZ DA TEORIA FILOSÓFICA-POLÍTICA DO COMUNitARISMO. CONTUdo, É POSSÍVEl PERCEBER ELEMENTOS QUE ACARRETARAM UMA CRISE DE IDENTIDADE NO EXERCícIO dAS ATIVIDADES dO SUPREMO. ESSA CRISE DE IDENTIDADE SE INTENSIFICA COM O INSTITUTO DO AMICUS CURIAE QUESTIONANDO O PAPEL COMO TRIBUnal CONSTITUCIONAL PROPRIAMENTE DITO.

\section{PALAVRAS-CHAVE}

SUPREMO TRIBUNAL FEDERAL; COMUNITARISMO; DEMOCRACIA PARTICIPATIVA; CIDADANIA; AMICUS CURIAE.

\section{ABSTRACT}

THE 1988 CONSTITUTION CONFERRED TO THE SUPREME COURT AN INSTITUTIONAL DESIGN THAT REFLECTS A VALORIZATION OF THE CONSTITUTIONAL TEXT AND AN EFFORT TO BRING IT NEAR TO A CITIZENSHIP PRACTICE DUE TO A PARTICIPATIVE DEMOCRACY MOVEMENT, IN THE LIGHT OF THE OF THE COMMUNITARIAN PHILOSOPHICAL-POLITICAL THEORY. HOWEVER, IT IS POSSIBLE TO SEE ELEMENTS THAT UNLOOSE AN IDENTITY CRISIS ON THE ACTIVITIES DONE BY THE SUPREME. THIS IDENTITY CRISIS IS SHARPENED BY THE INSTITUTE OF THE AMICUS CURIAE, QUESTIONING THE ROLE AS A CONSTITUTIONAL TRIBUnal ITSELF.

\section{KEYWORDS}

SUPREME COURT; COMMUNITARISM; PARTICIPATIVE DEMOCRACY; CITIZENSHIP; AMICUS CURIAE. análise dos debates transcorridos durante a Assembleia Nacional Constituinte, em 1987/88, permite vislumbrar uma questão que poderá ser retomada agora, após vinte anos da promulgação do texto constitucional: o desenho institucional do Supremo Tribunal Federal.

É cediça a influência exercida por modelos europeus de controle de constitucionalidade, como o espanhol e o português, na "engenharia constitucional" de 1988. Contudo, as peculiaridades do debate brasileiro, incluindo a necessidade premente de solução das divergências entre os diferentes grupos políticos à época, fez que o Supremo Tribunal Federal não assumisse um papel de corte constitucional propriamente dito. 
Entretanto, o aumento da legitimidade ativa para propor a principal ação do sistema de controle de constitucionalidade foi considerado um avanço na influência exercida pelo comunitarismo e pelas ideias da "comunidade de intérpretes" de Peter Häberle (1997).

Dessa feita, o presente artigo visa refletir sobre como o Supremo apreendeu a nova concepção dada ao controle de constitucionalidade concentrado pela Constituição de 1988 e em que medida o instituto do amicus curiae permite a retomada das discussões acerca da relevância do papel político do Supremo como corte constitucional strictu sensu, e não como mais uma instância recursal.

Para tanto, faremos uma contextualização teórica do novo parâmetro constitucional utilizado por ocasião da Assembleia Nacional Constituinte de 1987 para o desenho institucional do Supremo. Em seguida, passaremos à análise da forma como o Supremo compreendeu esse novo papel, em especial a partir da legitimidade ativa. E, por fim, traçaremos reflexões sobre a relação entre a teoria, a prática jurisdicional e o novo instituto do amicus curiae, a fim de buscar possibilidades institucionais para o futuro.

\section{NOVO PARADIGMA CONSTITUCIONAL}

As Constituições do século XX, em especial após a Segunda Guerra Mundial, já podem ser consideradas "políticas". Diante do pluralismo das sociedades contemporâneas, da necessidade de se defender o reconhecimento e a igualdade, o político é reabilitado nos estudos da teoria constitucional. Assim, a Constituição passa a ser vista como uma ordem integradora, que expressa valores e princípios, ressaltandose o seu caráter dinâmico e "politizando" o texto constitucional. Isso se deve a uma série de fatores de cunho teórico mais pertinentes às esferas sociológicas e políticas, que passaremos a debater.

Nas sociedades modernas houve uma reestruturação do núcleo valorativo dominante: do princípio hierárquico (diferenciação) passou-se à noção de dignidade. Essa nova lógica propõe a igualdade de todos os seres humanos, fundada na capacidade destes de autonomamente guiarem suas próprias existências e instituírem os princípios reguladores da vida social. Em sociedades hierárquicas, o conceito que predomina é o da honra, associada à expressão de um status, da demarcação de fronteiras com indivíduos tidos como inferiores. Em contrapartida, a dignidade está dissociada de qualquer papel social, atrelada apenas à ideia do self, da autonomia (BERGER, 1983).

Entretanto, a descoberta da autonomia individual, da dignidade a partir do "ser" individual, independente de qualquer posição ou identificação social, pode acarretar uma certa sensação de "alienação" e uma crise de identidade (BERGER, 1983). Luís Roberto Cardoso de Oliveira (1995) destaca que há a necessidade de se "discutir a 
dimensão substantiva da solidariedade, indissociável da esfera do vivido ou das representações culturais que lhe dão sentido, e constitutiva da identidade de qualquer pessoa ou cidadão" (p. 2-3). Ademais, é preciso reconhecer a dignidade do cidadão enquanto membro de uma comunidade, "onde a identidade dos cidadãos tenha um mínimo de substância que lhes garanta um tratamento que não seja estritamente formal e coisificador" (p. 16).

Assim, é possível distinguir duas percepções do direito: o direito neutro face aos sistemas particulares de valor, e um direito inserido em um sistema comum de crenças, regras e valores:

O direito à igual consideração e respeito surge-nos, nas discussões políticas, como absolutamente claro: todo ator possui o direito a realizar escolhas, embasando-se nas liberdades individuais estruturadoras do cerne procedimental do liberalismo contemporâneo. A reivindicação pelo elemento solidário enquanto componente da cidadania, por seu turno, pode se tornar mais transparente à medida em que enfatizemos a noção de cidadania enquanto pleno pertencimento a uma sociedade nacional, o que significa tematizar processos de integração social. Ponderações de linha comunitarista buscam dar conta do fato de que o acordo procedimental por si só não seria competente para manter os vínculos sociais suficientemente estreitos. A fim de que se alcançasse uma vida em comum minimamente estruturada, far-se-iam necessários, ao lado de estruturas formais da justiça, laços cujo locus é encontrado na esfera dos costumes. (SOUSA, 1999 , p. 27)

A partir da noção de liberdade é que se adensam os debates. A questão pode ser resumida da seguinte forma: "o individualismo liberal representa a reivindicação de uma liberdade que somente pode ser definida de modo negativo" (não interferência), enquanto os "republicanos" defendem a não interferência apenas contra o arbitrário, proclamando um aspecto social e holístico da liberdade, o que "significa defender uma dupla tese: a do reconhecimento e da igualdade” (BERTEN, 2003, p. 23-4).

Portanto, o elemento central do debate passa a ser as razões que os cidadãos podem ter para participar ativamente do destino de seu país: para protegê-lo da interferência estatal (razões liberais) ou como condição do exercício da liberdade individual mediante o exercício da "virtude cívica" e da dedicação a uma comunidade política. É neste viés do debate, a participação do cidadão, que concentraremos nossa análise, e não na polêmica de cunho filosófico sobre a moral e a justiça propriamente dita. Nosso objetivo é a reflexão sobre as questões de justificação do papel exercido pelo Supremo Tribunal Federal com a promulgação da Constituição de 1988. 
Após essa definição preliminar do contexto teórico ora utilizado, faz-se necessário abordar a teoria política conhecida como comunitarismo, que se insere em um debate de cunho filosófico-político entre liberais e comunitaristas. De maneira geral, na presente discussão os liberais são representados por John Rawls (1997; 2000) e apregoam a primazia do indivíduo, enquanto os comunitaristas, representados principalmente por Charles Taylor (2000) e Michael Walzer (1990; 2003), defendem a importância das identidades sociais. Desse ponto de partida contraditório, emergem distintas concepções em torno do que seria o ideal de uma sociedade justa e as suas implicações normativas.

Contudo, o ponto convergente entre os principais teóricos que abordam a polêmica liberal-comunitarista, como J. Rawls (1997; 2000), Michael Walzer (1990; 2003), Charles Taylor (2000), A. MacIntyre (1984), J. Habermas (1997; 2002), é “a possibilidade de construir um discurso público e democrático que consiga compatibilizar o universal ao particular numa sociedade pluralista e fracionada por inúmeras concepções de bem, de justiça e de democracia” (LOIS, 2005, p. 24). O foco principal, portanto, residirá na influência do debate na construção da relação entre o campo jurídico e os campos político e social, em especial no "tipo ideal” de participação cidadã. ${ }^{1}$

Esse ponto convergente está inserido em outra importante temática: o movimento do "retorno ao Direito", que tem como característica a insistência por um fundamento ético para a ordem jurídica, em meio à retomada do direito como elemento integrante de uma perspectiva emancipatória (SCHMIDT, 2007).

Esta retomada surge a partir da necessidade de se buscar a significação de pluralismo nas sociedades democráticas contemporâneas. Enquanto o pensamento liberal interpreta o pluralismo a partir do indivíduo, o comunitarista insiste na primazia das identidades sociais. Assim, a controvérsia se expande para outras significações, como democracia, tendo em vista que as:

[...] realidades democráticas contemporâneas não têm exatamente na identidade sua marca. Ao contrário, são altamente caracterizadas pelas diferenças e desacordos de distintos grupos culturais e sociais, visões de mundo, concepções individuais, etc., que compõem um cenário pluralista no qual qualquer consenso há de enfrentar sempre situações conflitivas. (SCHMIDT, 2007)

Estas discussões retomam, ainda, a controvérsia entre a "liberdade dos antigos" e a "liberdade dos modernos": ${ }^{2}$ a primeira, proveniente da concepção rousseauniana de uma sociedade homogênea e da vontade comum suprema; a segunda tem como marco a ideia de um sujeito autônomo, senhor de si e construtor de sua própria história, cuja necessidade jurídica imediata é ver sua liberdade, do tipo deixar agir não 
obstruída, e tem como marco Locke (TAVARES, 2005). ${ }^{3}$ Esses dois marcos têm balizado o debate sobre a legitimidade constitucional.

Não existe democracia política sem a garantia constitucional dos direitos e liberdades fundamentais. A discussão em torno do ideal de justiça conveniente ao pluralismo do mundo se inicia focalizando o político e o sociológico, mas acaba por adentrar no âmbito do jurídico, pois não há como configurar e justificar um ideal de justiça sem que se encare, simultaneamente, a questão do papel da Constituição, de sua efetivação, dos direitos fundamentais e da atuação do Poder Judiciário. (TAVARES, 2005, p. 113)

Ademais, paralelamente aos debates mencionados acima, sobre o conceito de comunidade e suas decorrências entre liberais e comunitaristas, incorporaram-se novos temas, em especial sobre as práticas jurídico-constitucionais, como interpretação constitucional, controle de constitucionalidade, sistema de direitos, direitos humanos, entre outros. E é diante deste arcabouço teórico de cunho sócio-político que o presente artigo busca analisar o papel do STF diante da incorporação do modelo comunitarista por uma parte dos constitucionalistas brasileiros em 1988, ou seja, como o debate liberal-comunitarista influenciou temas mais próximos ao direito. ${ }^{4}$

Portanto, no tocante ao campo específico do direito, é importante salientar que comunitaristas como Taylor (2000) e Walzer (1990, 2003) acreditam que os direitos fundamentais constitucionalmente assegurados traduzem mais vontade e autodeterminação da comunidade do que um espaço de independência individual contra arbitrariedades estatais (liberdades negativas). Assim, “o sistema de direitos constitucionais assegura as liberdades positivas enquanto capacidade de determinação e controle de uma existência conjunta” (CITTADINO, 2000, p. 161).

Nessa linha de argumentação, o próprio significado de constituição reflete um projeto comum, um sentimento compartilhado, uma identidade e uma história comuns de determinada sociedade. Os direitos fundamentais compreendidos como liberdades positivas demandam, em essência, uma cidadania ativa, participativa no processo de deliberação pública.

Para amparar esta compreensão, Taylor (2000) aponta a necessidade de uma identificação patriótica, o sentimento de pertencimento a uma comunidade de valores compartilhados. A falta de percepção da força e importância da comunidade na vida dos sujeitos acarretaria o desinteresse público, um problema do pensamento liberal. Isso porque a política passaria a ser um mal necessário, "resultado da convivência entre sujeitos livres, iguais e racionais", pois optaram por um plano racional de vida, vendo o espaço público com o exclusivo propósito de atender a essas demandas (LOIS, 2005, p. 26). 
O que aflora no debate é, portanto, uma nova visão da própria significação de cidadania e participação, a noção de atitude (SCHMIDT, 2007). E essa visão poderá ser interpretada, no âmbito da jurisdição constitucional, como uma compreensão dos mecanismos e das qualidades da autonomia pública enquanto projeto de elevação das formas de existência social. E a sua realização não pode ser orientada por uma teoria do direito que se sustenta na imparcialidade alcançada pela obrigatoriedade de critérios racionais supostamente universais.

Este novo cenário pode ser apontado como um dos motivos do recente desenvolvimento da ideia de justiça constitucional, proliferando a criação de tribunais constitucionais em países em processo de consolidação democrática após períodos de autoritarismo. Os tribunais constitucionais representam o mecanismo que a sociedade civil possui para garantir que os valores e princípios apregoados no texto constitucional sejam "protegidos" por um sistema que é conhecido como controle concentrado de constitucionalidade. No Brasil, a influência comunitarista é perceptível nos trabalhos da Constituinte, e o próprio surgimento do controle de constitucionalidade concentrado implica em uma valorização do texto constitucional, que abrange não apenas o Estado, mas também a sociedade, os princípios de legitimação do poder, em um processo de "politização" do texto constitucional (GARCÍA-PELAYO, 1993, apud BERCOVICI, 2003, p. 104). Associada a esta valorização, a teoria da "sociedade aberta dos intérpretes da Constituição”, de Peter Häberle (1997), é apontada como principal fonte teórica do desenho institucional concedido ao Supremo sobre o controle de constitucionalidade.

Häberle (1997) rejeita a interpretação constitucional como um "evento exclusivamente estatal", inserindo todos, mesmo aqueles que não são diretamente afetados por ela.

Do ponto de vista teorético-constitucional, a legitimação fundamental das forças pluralistas da sociedade para participar da interpretação constitucional reside no fato de que essas forças representam um pedaço da publicidade e da realidade da Constituição, não podendo ser tomadas como fatos brutos, mas como elementos que se colocam dentro do quadro da Constituição: a integração, pelo menos indireta, da "res publica"na interpretação constitucional em geral é expressão e conseqüência da orientação constitucional aberta no campo de tensão do possível, do real e do necessário. Uma Constituição que estrutura não apenas o Estado em sentido estrito, mas também a própria esfera pública, dispondo sobre a organização da própria sociedade e, diretamente, sobre setores da vida privada, não pode tratar as forças sociais e privadas como meros objetos. (p.33)

Portanto, para o autor, limitar a hermenêutica constitucional aos intérpretes “corporativos", ou autorizados jurídica ou funcionalmente pelo Estado, significaria um 
empobrecimento do próprio conteúdo democrático da Constituição. Isso porque a questão da legitimação da Constituição perpassa pela teoria da democracia, e esta percebe o povo não apenas como um referencial quantitativo que se manifesta no dia da eleição, mas "também [como] um elemento pluralista para a interpretação que se faz presente de forma legitimadora no processo constitucional: como partido político, como opinião científica, como grupo de interesse, como cidadão" (HÄBERLE, 1997, p. 37).

Nota-se a conexão entre o pensamento de Häberle e o comunitarismo filosóficopolítico: ambos defendem um adensamento da democracia a partir de um ativismodo cidadão, além da sua participação nas eleições. E, para Häberle (1997), essa participação ocorre na própria "guarda" do texto constitucional; a teoria da Constituição e da hermenêutica propicia uma mediação específica entre Estado e sociedade:

Todo aquele que vive no contexto regulado por uma norma e que vive com este contexto é, indireta ou, até mesmo diretamente, um intérprete dessa norma. O destinatário da norma é participante ativo, muito mais ativo do que se pode supor tradicionalmente, do processo hermenêutica. Como não são apenas os intérpretes jurídicos da Constituição que vivem a norma, não detêm eles o monopólio da interpretação da Constituição. (p. 15)

Portanto, o autor atrela a interpretação constitucional a uma teoria democrática à ideia de uma sociedade pluralista, que, por sua vez, está associada à noção de Constituição e realidade constitucional. Essa percepção de realidade constitucional implica a valorização do papel da Constituição como forma não apenas de estruturação do Estado, mas da própria esfera pública, não podendo "tratar as forças sociais e privadas como meros objetos. Ela deve integrá-las ativamente enquanto sujeitos” (HÄBERLE, 1997, p. 33). Trata-se de integrar as forças da comunidade política no processo de interpretação constitucional.

Assim, integramos as duas premissas, a do valor atribuído ao texto constitucional e à "comunidade de intérpretes" e do comunitarismo filosófico-político explicitado anteriormente. Trata-se de realçar a importância da participação do cidadão nos contextos políticos, que incluem a própria Constituição, norma de conteúdo político e que, consequentemente, demanda uma interpretação a qual vai além do jurídico exclusivamente.

Consoante Oscar Vilhena Vieira (1994), entre as alterações na esfera da jurisdição constitucional e do controle da constitucionalidade que contribuíram para a ampliação do papel político-institucional do STF destacam-se: a ampliação dos agentes legitimados a propor a ação direta de inconstitucionalidade e a autonomia entregue ao Ministério Público Federal, que tornaram o Supremo uma arena política mais acessível, reforçando suas funções tradicionais de garantir o processo democrático e assegurar a supremacia da Constituição frente às decisões majoritárias 
e governamentais; a criação de instrumentos voltados a garantir a eficácia dos direitos constitucionais que dependam de regulamentação, para que possam ser adequadamente exercíveis; a ampliação das hipóteses de controle material da constitucionalidade de emendas à Constituição, que coloca o STF em posição de controlar as decisões do próprio poder constituinte reformador; e a Emenda Constitucional $\mathrm{n}^{\circ}$ 3, de 1993, que introduziu a ação declaratória de constitucionalidade.

O controle de constitucionalidade pode ser resumido como um sistema que visa proteger o texto constitucional. Assim, todo o ordenamento jurídico deverá observar o conteúdo constitucional. Quando surge uma contradição entre um ato normativo e a Constituição, competirá ao Poder Judiciário declará-lo inconstitucional. Isto pode ser feito de duas formas: mediante um órgão específico, criado para este fim, conhecido como Corte Constitucional e cuja decisão refletirá no ato normativo em si, alcançando toda a sociedade, por meio da Ação Direta de Inconstitucionalidade (ADI) - conhecido como modelo concentrado; ou mediante qualquer juiz, mas cuja decisão refletirá apenas no processo analisado, sem declaração de inconstitucionalidade do ato normativo propriamente dito - o modelo difuso.

O Brasil adotou os dois modelos: o STF é o tribunal específico para declarar um ato normativo inconstitucional com reflexo para toda a sociedade, mediante a retirada da norma do ordenamento jurídico, mas um juiz poderá julgar um caso específico e, apenas com relação a esse caso, declarar determinado dispositivo legal inconstitucional, com efeito apenas para as partes envolvidas no caso/processo.

O modelo concentrado transparece a importância que o respectivo sistema concede ao texto constitucional e, consequentemente, a sua função política e simbólica - a consciência de direitos e a afirmação da capacidade para reivindicá-los, ou seja, uma forma de exercício da cidadania e da participação política.

A ênfase na participação do cidadão, portanto, é um dos paradigmas constitucionais que retomamos no presente artigo. Isso porque, conforme mencionado, atribui-se à teoria filosófico-política do comunitarismo uma forte influência no desenho constitucional brasileiro de 1988. Para tal teoria, é necessária a configuração de valores compartilhados por certa comunidade política, o que justificaria um envolvimento por parte do cidadão além do momento de participação nas eleições. No Brasil, atribui-se ao comunitarismo jurídico brasileiro a luta pela democratização do processo de interpretação constitucional através do alargamento da comunidade de intérpretes da Constituição, isto é, o rol de agentes legitimados/aptos a propor a ADI com vistas a assegurar uma cidadania substancialmente participativa, o papel do cidadão enquanto "autor" do direito.

Para o comunitarismo, quando o cidadão sente que o poder está a uma grande distância de si e deixa de ser responsivo, ocorre o fenômeno da fragmentação política. Isso até pode ocorrer em sociedades caracterizadas por um alto nível de batalhas judiciais, mas estas refletem um fenômeno conhecido como direito em abundância: o 
aumento do número e da variedade de atores jurídicos, da quantidade de material normativo, da amplitude atingida pela teoria jurídica, da quantidade de informação disponível, dos gastos com os serviços jurídicos e da consequente intensidade do trabalho produzido pelos advogados etc. (GALANTER, 1993).

Dessa feita, o comunitarismo surge como uma defesa do exercício da diversidade mantida por ideais comuns motivadores, os quais redundam em uma participação comprometida. Cumpre salientar, entretanto, que o comunitarismo não deve ser confundido com uma tentativa nostálgica de reconstruir certa noção primordial e abrangente de consenso moral, ou como um retorno às comunidades tradicionais. $\mathrm{Na}$ verdade, é sim uma tentativa de reformular o ideal democrático em uma sociedade moderna, altamente pluralista, mas não necessariamente fragmentada.

No âmbito do controle de constitucionalidade e da justiça constitucional, a análise da participação do cidadão realça a importância desta nos contextos políticos, que incluem a própria Constituição, norma de conteúdo político e que, consequentemente, demanda uma interpretação a qual vai além do jurídico exclusivamente.

A partir do novo paradigma apontado, surgem análises sobre a forma como ele foi implementado. No cenário político-jurídico brasileiro grande parte das análises vê o processo de judicialização da política ${ }^{5}$ como a possibilidade de concretização de uma cidadania ativa:

Estender a elas [maiorias], agora, como se deu a partir da Carta de 1988, o acesso aos procedimentos que levam à elaboração das leis, e mesmo ao controle da sua produção, permitindo-lhes combinar as ações da sua vida associativa e dos seus órgãos de representação com essas instituições que admitem as grandes massas como novos personagens da esfera pública, se vem apresentando como um caminho inédito, em que a república se recria por baixo, enraizada nos interesses e nas expectativas de direitos do que até agora foi o limbo do Brasil. (VIANNA; CARVALHO, 2002, p. 153)

Nesse sentido, atribuiu-se ao direito, em especial ao poder judiciário, um novo papel, um papel predominante na própria concretização da democracia e da cidadania, fruto de uma abordagem em que o juiz surge como o recurso contra a implosão das sociedades democráticas as quais não conseguem administrar de outra forma a complexidade e a diversificação que elas mesmas geraram. Ele é o último "guardião de promessas", tanto para o sujeito como para a comunidade política, diante da crise de legitimidade do Estado. A sociedade tem se remetido aos juízes por conta da ausência de autoridade, passando a preencher a função de instituição unificadora (GARAPON, 1992). ${ }^{6}$

Assim, expressões correlatas, como judicialização da política, e politização da justiça, buscam indicar os efeitos da expansão do poder judiciário no processo decisório 
das democracias contemporâneas. Vanessa Oliveira (2005) aponta o que chama de ciclo da judicialização, composto de três fases: "primeiramente no acionamento do Judiciário através do ajuizamento de processos - ou politização da justiça; em segundo lugar, no julgamento do pedido de liminar (quando houver); e por fim, no julgamento do mérito da ação, que enseja a judicialização da política propriamente dita" (p. 560). ${ }^{7}$

Portanto, nas análises do fenômeno no Brasil, ${ }^{8}$ defende-se que o poder judiciário deixou de ser um poder periférico, encapsulado em uma lógica com pretensões autopoiéticas inacessíveis aos leigos, distante das preocupações da agenda pública e dos atores sociais. Werneck Vianna et al. (1999) aponta que o judiciário "se mostra uma instituição central à democracia brasileira, quer no que se refere à sua expressão propriamente política, quer no que diz respeito à sua intervenção no âmbito social". Seria uma "vocação expansiva do princípio democrático que tem implicado em uma crescente institucionalização do direito na vida social, invadindo espaços até há pouco inacessíveis a ele”.

Werneck tomou o termo para descrever as transformações constitucionais após 1988, que permitiriam o maior protagonismo dos tribunais em virtude da ampliação dos instrumentos de proteção judicial e que teriam sido descobertas por minorias parlamentares, governos estaduais, associações civis e profissionais. ${ }^{9}$ Podemos atribuir a essa abordagem um forte componente comunitarista, ao defender que o Poder Judiciário surge como alternativa para a resolução de conflitos coletivos, para a agregação do tecido social e mesmo para a adjudicação de cidadania.

Em torno do poder judiciário surge uma arena pública externa ao circuito clássico sociedade civil-partidos-representação-formação da vontade majoritária, colocando o Judiciário diante de uma interpelação direta de indivíduos, de grupos sociais e até de partidos, em um tipo de comunicação na qual prevalece a lógica dos princípios (VIANNA et al., 1999). Essa lógica de princípios é inerente ao ideal comunitarista, como vimos.

Na nossa opinião, entretanto, o aumento da demanda não está necessariamente atrelado a uma efetiva intenção participativa do cidadão brasileiro, e as estatísticas do Supremo refletem mais uma crise de quantidade nesse sentido, conforme exploraremos a seguir.

Ademais, nossa análise resgata a necessidade que a nova compreensão da Constituição, e do próprio papel dos tribunais, demanda: uma nova prática interpretativa, de caráter construtivo, em que o poder judicial esteja consciente de seu papel na configuração de uma democracia mais participativa.

Nesse sentido, o poder judicial deixa de ser um instrumento apenas do Estado, passando a ser, também, da sociedade, o que acarreta uma politização do direito. O discurso da neutralidade utilizado pelos atores jurídicos passa a ser questionado, principalmente quando o objeto de análise é a relação entre direito e política, admitindo-se 
aqui direito como o texto normativo e sua interpretação por intermédio do Poder Judiciário, e Política como as teorias filosóficas-políticas que influenciam a elaboração do texto normativo. Essas teorias filosóficas-políticas compreendem o pano de fundo das novas abordagens sobre o papel da constituição.

\section{ANÁlise JuRisprudenCial}

A ampliação dos agentes legitimados para acionar diretamente o Supremo é considerada um avanço no sentido de permitir que o STF esteja mais aberto às demandas de diversos setores políticos, sociais e corporativos, retirando-se da esfera do Estado a exclusividade da capacidade postulatória, na linha apregoada pelo comunitarismo, conforme salientamos anteriormente. Assim, permitiu-se que minorias sejam representadas por intermédio de seus partidos, sindicatos ou entidades de classe, expressando seu repúdio a atos contrários à Constituição. Essa ampliação expandiu o papel do STF enquanto arena política, na qual diversos grupos disputam a realização ou o bloqueio de dispositivo constitucional.

Tabela 1 - Ações Diretas de Inconstitucionalidade por Legitimado - 1988 a 2008*

LEGITIMADOS QUANTIDADE PERCENTUAL

\begin{tabular}{|c|c|c|}
\hline PRESIDENTE DA REPÚBLICA & 6 & $0,1 \%$ \\
\hline MESA DO SENADO FEDERAL & 1 & $0,0 \%$ \\
\hline MESA DA CÂMARA DOS DEPUTADOS & 0 & $0,0 \%$ \\
\hline MESA DA ASSEMBLEIA LEGISLATIVA OU CÂMARA LEGISLATIVA DO DISTRITO FEDERAL & 43 & $1,0 \%$ \\
\hline GOVERNADOR DE ESTADO OU DO DISTRITO FEDERAL & 1.044 & $25,5 \%$ \\
\hline PROCURADOR-GERAL DA REPÚBLICA & 891 & $21,7 \%$ \\
\hline CONSELHO FEDERAL DA OAB & 166 & $4,0 \%$ \\
\hline PARTIDO POLÍTICO COM REPRESENTAÇÃO NO CONGRESSO NACIONAL & 734 & $17,9 \%$ \\
\hline CONFEDERAÇÃO SINDICAL E ENTIDADE DE CLASSE DE ÂMBITO NACIONAL & 876 & $21,4 \%$ \\
\hline MAIS DE 1 LEGITIMADO ** & 3 & $0,1 \%$ \\
\hline OUTROS (ILEGITIMADOS) & 337 & $8,2 \%$ \\
\hline TOTAL & 4.101 & $100,0 \%$ \\
\hline
\end{tabular}

Fonte: Portal de Informações Gerenciais do STF.

* Dados de 2008 atualizados até junho.

** Confederação Sindical e Partido Político.

Infere-se da tabela 1 a assertiva anterior, de que o Supremo se tornou uma arena política mais ampliada e acessível. Entre os legitimados com maior número de ações, dois representam interesses mais relacionados com o coletivo, mesmo que de forma corporativa, como é o caso das confederações sindicais e entidades de classe. Inicialmente, o Procurador-Geral da República detinha o monopólio da ação, do que 
se infere o grande avanço instituído pela Constituição de 1988, ainda que o Supremo em algumas oportunidades restringisse essa participação mais "popular", conforme salientaremos adiante.

Um exemplo de tal restrição é o entendimento do Supremo no tocante a União Nacional dos Estudantes (UNE). A entidade associativa dos estudantes universitários, cujo histórico é de ativa participação em movimentos cívicos nacionais na defesa das liberdades públicas, de âmbito nacional, e na defesa de interesses estudantis, não é legítima para propor a ADI, no entendimento do STF, pois não detém a condição de entidade de classe de âmbito nacional, compreendendo-se classe como um "conteúdo imediatamente dirigido à ideia de profissão, como categoria profissional, e não no sentido de simples segmento social, de 'classe social'”. 10

Quanto ao Recurso Extraordinário (RE), este exerce a função de guardião da constituição, nas causas decididas em única ou última instância, quando a decisão recorrida contrariar dispositivo constitucional, declarar a inconstitucionalidade de tratado ou lei federal, ou julgar válida lei ou ato de governo local contestado em face da Constituição (art. 102, III, e alíneas). Cumpre salientar aqui a visão processual deste recurso: trata-se de um recurso que não visa à correção da injustiça do julgado recorrido (MANCUSO, 1996).

Quando a nova Carta Magna Brasileira criou o Superior Tribunal de Justiça (STJ), que absorveu parte das competências que a Constituição anterior conferia ao STF, retiraram-se do antigo Recurso Extraordinário as questões referentes à interpretação do direito federal e à supremacia deste, que passaram a ser objeto de recurso especial para o STJ. Ao STF assegurou-se a exclusividade no tocante a questões relativas estritamente à constitucionalidade. No entanto, ainda que a intenção fosse positiva, a medida explicitada acima retardou ainda mais o curso da Justiça no Brasil, pois criou-se uma quarta instância.

Portanto, após desenrolar-se a primeira instância perante o juiz singular, há a segunda, perante um tribunal, e se segue para as duas cortes superiores, ainda que em termos de agravo de despacho denegatório de Recurso Especial (REsp) ou de Recurso Extraodinário (RE). Além disso, quando houver matéria constitucional envolvida, a parte deverá interpor, simultaneamente, o REsp para o STF e o RE para o STF, aguardando a apreciação do primeiro para só então discutir a matéria constitucional, o que exige a interposição antecipada de recurso, que, possivelmente, não será necessário caso a questão possa ser resolvida na esfera da legislação infraconstitucional. Conforme ensinamento de José Antônio Pimenta Bueno (1978) sobre as dificuldades inerentes a uma terceira instância, principalmente quanto à insegurança jurídica:

Com efeito, criar mais de duas instâncias seria não atender os verdadeiros interesses sociais, fora onerar muito as partes, conservar por muito tempo 
os direitos e as fortunas em dubiedade e deterioração, e enfim não impor oportunamente um termo às questões. Demais, se duas instâncias podem laborar em erro, ou parcialidade, nada evitaria que uma terceira fosse quem nesse defeito incorresse. O último julgado seria sempre obra dos homens, e como tal sujeita à sua falibilidade e imperfeição. (p. 337)

É justamente esta insegurança e lentidão processual que a sociedade mais critica, que imprime uma certa "impunidade" aos olhos do cidadão comum, o qual, ao recorrer à Justiça, precisa aguardar longos anos por uma solução. E, como o Supremo também é o "guardião" da Constituição, torna-se patente uma crise de identidade, pois para o cidadão ele acaba não exercendo plenamente nenhuma das duas atividades, ainda que esteja totalmente sobrecarregado, mas mais como instância recursal do que como Tribunal Constitucional propriamente dito.

Isso porque o STF não seria simplesmente mais um tribunal superior, e sim a Corte Suprema, encarregada de manter o império e a unidade do direito constitucional, além de o próprio RE não constituir mais uma possibilidade de impugnação, e sim um remédio de cunho político-constitucional, uma vez que seus pressupostos não estão na lei processual. Assim, ao Supremo cabe assegurar a inteireza positiva do direito constitucional, provendo o recurso não porque é injusta, mas sim porque fere a constituição, e resolvendo, portanto, a situação jurídica individual em segundo plano.

Para comprovar o acúmulo de serviço no STF, utilizamos dados disponíveis no site do Tribunal sobre a movimentação processual nos últimos vinte anos, em intervalos de cinco anos, incluindo até junho de 2008:

Tabela 2 - Movimentação Processual no Supremo 1989, 1994, 1999, 2004, 2008*

\begin{tabular}{lcccccc}
\multicolumn{2}{l}{ MOVIMENTAÇÃO PROCESSUAL STF } & $\mathbf{1 9 8 9}$ & $\mathbf{1 9 9 4}$ & $\mathbf{1 9 9 9}$ & $\mathbf{2 0 0 4}$ & $\mathbf{2 0 0 8}$ \\
\hline PROCESSOS PROTOCOLADOS & 14.721 & 24.295 & 68.369 & 83.667 & 54.877 & \\
\hline PROCESSOS DISTRIBUÍDOS & 6.622 & 25.868 & 54.437 & 69.171 & 40.081 & \\
\hline JULGAMENTOS & 17.432 & 28.221 & 56.307 & 101.690 & 70.172 & \\
\hline ACÓRDÃOS PUBLICADOS & 1.886 & 7.800 & 16.117 & 10.674 & 9.174 \\
\hline
\end{tabular}

Fonte: Portal de Informações Gerenciais do STF.

* Dados de 2008 atualizados até junho.

Os dados refletem que atualmente o Supremo despende muito mais tempo com Agravos de Instrumento, de natureza processual, uma vez que é cabível quando não for admitido o Recurso Extraordinário no tribunal de origem, em vez de ADI, que tem maior afinidade com a sua função máxima de guardião da Constituição. ${ }^{11}$

A Constituição Federal de 1988 incorporou inúmeras matérias anteriormente tratadas em textos infraconstitucionais, o que ampliou consideravelmente o leque de 
questões permissíveis de interpelação junto ao STF via Recurso Extraordinário, do que decorre o volume desproporcional de Recursos Extraordinários, e os respectivos Agravos de Instrumentos, quando aqueles não são acolhidos. ${ }^{12}$ Apesar da criação do STJ, cuja função é a uniformização de jurisprudência em torno da legislação federal, permitindo que o STF possa assumir feições de Corte Constitucional, como guardião da Carta Magna, não se criou mecanismo de seleção das causas a serem julgadas pelo Supremo, solução que vários autores apontam como primordial para o desafogamento da Corte Suprema.

Dallari (1996) destaca que foi proposta à Assembleia Nacional Constituinte a criação de um Tribunal Constitucional, restrito ao controle de constitucionalidade das leis e atos de autoridades públicas, bem como a promoção da responsabilidade dos que praticassem atos contrários à Constituição. Contudo, o autor destaca que o STF se manifestou contrariamente à criação daquele tribunal, pois diminuiria o seu "prestígio".

Portanto, podemos apontar a permanência como última instância recursal como um dos entraves para o fiel exercício das atribuições constitucionais pelo Supremo, desconfigurando-o como um Tribunal Constitucional strictu sensu. Ademais, o próprio Supremo, levado por boas intenções diante da absurda quantidade de trabalho, restringe sua atuação mais próxima do cidadão. Isso pode ser exemplificado através de duas interpretações quanto à legitimidade ativa nas ações diretas de inconstitucionalidade:

a) O STF tem interpretado o termo confederações e entidade de classe de forma restritiva, tendo como objetivo limitar o número dos legitimados. A interpretação restritiva do Supremo, que limita o acesso destes entes, é baseada em princípios do direito do trabalho e da ideia de que tais entes são de direito privado. A primeira restrição é quanto ao conceito de confederação sindical, que deverá observar a Consolidação das Leis do Trabalho (CLT), artigos 533 e 535. Assim, o STF entendeu que centrais sindicais não integram a pirâmide em que se estrutura a organização sindical. Para o Supremo, as centrais sindicais são associações civis licitamente constituídas por entidades sindicais e associações profissionais de trabalhadores de qualquer categoria. Isso porque, assim como é permitido ao trabalhador, paralelamente à sindicalização, constituir associações profissionais, é permitido às entidades sindicais a liberdade de associar-se para a coordenação da defesa de interesses comuns, "independentemente de sua integração paralela no sistema confederativo, a cujos integrantes se reservam com exclusividade os poderes jurídicos de representação sindical". ${ }^{13}$ A CLT estabelece o sistema confederativo, que significa a possibilidade de associação no nível de sindicatos, federações e confederações, e dominado pelo princípio básico da unicidade, nos diversos graus, de representação da categoria ou grupo de categorias. Assim, a estrutura é vertical e em três níveis. A confederação sindical seria de grau superior, 
ocupando o ápice da hierarquia da estrutura sindical. Nesse sentido, centrais sindicais não estão inseridas em tal estrutura, fazendo parte, sim, do princípio constitucional que assegura o direito de associação às pessoas físicas.

b) $\mathrm{Na}$ mesma linha interpretativa, tem-se exigido que as confederações sindicais e as entidades de classe de âmbito nacional, para propor ações diretas de inconstitucionalidade, devem preencher o requisito objetivo da relação de pertinência entre o interesse específico da classe ou categoria, para cuja defesa essas entidades são constituídas, e a lei ou o ato normativo, cuja inconstitucionalidade é arguida. Deve haver uma vinculação das finalidades estatutárias da parte com a lei ou ato normativo que se almeja impugnar. Trata-se de requisito sem nenhum amparo constitucional, ferindo inclusive o princípio da igualdade, pois não se requer tal relação de pertinência a respeito dos demais órgãos ou pessoas legitimados pelo artigo 103. O ministro Celso de Mello, na ADI n ${ }^{\circ} 42$, assim define a restrição:

Um outro aspecto merece referência e diz respeito ao interesse de agir das entidades de classe, a envolver a necessidade de que demonstrem, objetivamente, a relação de pertinência entre a finalidade institucional que motivou a sua criação e o conteúdo e a natureza da lei ou ato normativo impugnado. A descoincidência temática entre esses dois elementos referenciais - finalidade da associação e conteúdo material da lei ou ato normativo - descaracterizará o interesse de agir e ensejará a carência [negar prosseguimento] da ação direta.

Assim, percebe-se uma certa incoerência entre o texto constitucional, seus princípios e valores, de influência comunitarista, e a forma como o Supremo tem se manifestado, o que poderemos apontar como uma crise de identidade: ele acumula as funções de última instância recursal, que o sobrecarregam, com funções de Tribunal Constitucional strictu sensu, que se coadunam com a forma como o texto constitucional passou a ser valorizado.

\section{Novo instituto}

Podemos depreender do que foi até o momento exposto que uma nova configuração surge no tocante ao papel do juiz: este não é mais um mero instrumento do Estado, mas sim da sociedade, o que acarreta sua politização (QUEIROZ, 2000). Ademais, a Constituição não é garantida nem por um ordenamento jurídico acima dela, nem por uma coatividade supraestatal, mas sim por sua própria força e por suas próprias garantias. Assim, para que ela seja obedecida, é preciso que seja considerada moralmente correta, ou melhor, que seja legítima. É a conformidade da Constituição com 
os interesses, as aspirações e os valores de um determinado povo em determinado momento histórico que a legitima (HESSE, 1996).

Dessa forma, resgata-se, aqui, o dilema entre democracia participativa e democracia representativa. A democracia representativa se enquadra no modelo liberal de Estado, em que se enfatiza o procedimentalismo como método de constituição de governos. Já a democracia participativa, ou inclusiva, representa a reflexão sobre este mesmo procedimentalismo como prática social. A ideia de democracia participativa está associada à ideia de atitude por parte do cidadão, conforme descrevemos anteriormente.

Entretanto, apesar de o controle concentrado de constitucionalidade ser uma quase "universalidade", as cortes têm variado quanto à extensão em que estão dispostas a exercer esse poder na realidade. E o Brasil não é exceção. Como já explicitado, o desenho institucional do Supremo na Constituição de 1988 acabou por delimitar o exercício do poder democrático pelo Supremo. Ademais, a orientação jurisprudencial nos últimos vinte anos também foi no sentido de se afastar, de certa forma, das concepções de origem, como a influência comunitarista de ideias mais pluralistas, defendidas por Häberle.

Por isso, apontamos o instituto do amicus curiae, introduzido pela Lei $\mathrm{n}^{\circ}$ 9.868, de 11 de outubro de 1999, como um importante mecanismo de abertura constitucional, na linha defendida por Häberle (1997) da comunidade de intérpretes. Trata-se da possibilidade de determinados órgãos ou entidades se manifestarem acerca de matéria levada a julgamento, em caso de relevância da discussão e de representatividade do postulante (BARROSO, 2006). Assim, durante o processo de controle concentrado de constitucionalidade, representantes da sociedade civil podem se manifestar no processo, mesmo que não sejam partes legítimas para propor a ação. A finalidade precípua do amicus curiae é pluralizar o debate constitucional.

O amicus curiae não é parte direta no processo, é uma pessoa - física ou jurídica - que tem interesse moral na lide e pode contribuir, com suas informações e seus conhecimentos, para encontrar a melhor solução para o caso. E, nesse sentido, sua maior representatividade pode conduzir a debates mais próximos das demandas dos cidadãos. Não há exigência de pertinência temática nem de representação nacional. "Haverá sempre outras entidade de notória representatividade que, por isso, serão admitidas ao debate, dependendo apenas do tema discutido" (BUENO FILHO, 2002, p. 6). Portanto:

A admissão de terceiro na condição de amicus curiae, no processo adjetivo de controle normativo abstrato, qualifica-se como fator de legitimação social das decisões da Suprema Corte, enquanto Tribunal Constitucional, pois viabiliza, em obséquio ao postulado democrático, a abertura do processo de fiscalização concentrada de constitucionalidade, em ordem a 
permitir que nele se realize, sempre sob uma perspectiva eminentemente pluralística, a possibilidade de participação formal de entidades e de instituições que efetivamente representem os interesses gerais da coletividade ou que expressem os valores essenciais e relevantes de grupos, classes ou estratos sociais. (p. 5)

Nosso objetivo é analisar o instituto à luz do novo paradigma proposto pela Constituição de 1988, o comunitarista, e pelo novo papel atribuído ao Supremo com a valorização do texto constitucional, sem adentrar nas questões processuais. Portanto, retomando o que chamamos de crise de identidade, o novo instituto apresenta características que aproximam o Supremo do seu papel político e de guardião da constituição.

Entender a Constituição como não apenas normativa, mas também política.

Compreender as relações políticas e sociais presentes nas estruturas

constitucionais. Perceber que a Constituição pertence também á realidade

histórico-social. Tornar claros os nexos existentes entre Estado, Constituição

e política, concebendo o direito constitucional como direito político.

(BERCOVICI, 2003)

Essa seria a nova função atribuída aos tribunais constitucionais e aos textos constitucionais, em um movimento de valorização do caráter político de ambos, inclusive para o adensamento da democracia, principalmente no período após regime autoritário em alguns países.

\section{ReFleXÕeS FINAIS}

Importante destacar ainda que a existência de diferentes graus de jurisdição nem sempre garante a aplicação da Justiça. O princípio processual da garantia do direito de defesa, da possibilidade do contraditório, tem levado a exageros no sistema judiciário brasileiro, em que alguns processos passam por até quatro instâncias, consoante salientado anteriormente. O fundamento para a existência do mecanismo recursal é o fato de que, tomando como ponto de partida o direito positivo, as soluções possam ser diversas, assegurando-se, portanto, a diversidade de entendimentos e a possibilidade de mudanças de interpretação judicial.

Contudo, o uso de subterfúgios e de manobras protelatórias favorece quem tem mais recursos econômicos e pode contratar os melhores advogados, gastar mais dinheiro com a produção de provas e suportar por mais tempo uma demanda judicial, do que se infere que são os pobres os mais prejudicados com a distorção do princípio do duplo grau de jurisdição. Conforme salienta Dallari (1996): 
Ocorre, entretanto, que a prática já deixou comprovado que a possibilidade de ter o mesmo caso examinado e decidido em várias instâncias não significa, necessariamente, a possibilidade de decisões mais justas, sendo certo, em sentido contrário, que a longa, demorada e dispendiosa tramitação por várias instâncias acarreta conseqüências de ordem econômica que favorecem os mais ricos. (p. 106)

Portanto, uma análise do papel do Supremo durante os vinte anos desde a promulgação da Constituição de 1988, e suas implicações institucionais para o futuro, demanda considerar a engenharia constitucional de 1987 à luz da própria atuação do Supremo durante o período. $\mathrm{O}$ seu papel político o aproxima da ideia de democracia participativa, como guardião da Constituição e dos valores e princípios que ela enuncia.

A democracia participativa se insere no quadro da terceira onda de democratização, que trouxe à tona questões relacionadas ao problema da qualidade da democracia, a análise da democracia como substância, e não como forma. Trata-se de "uma tentativa de disputa pelo significado de determinadas práticas políticas, por uma tentativa de ampliação da gramática social e de incorporação de novos atores ou de novos temas à política” (SOUSA SANTOS; AVRITZER, 2002, p. 56).

Assim, adentramos o principal elemento defendido neste artigo: a participação, o papel da sociedade civil, dos movimentos sociais, na institucionalização democrática. Entretanto, esta nova percepção de democracia exige a constituição de uma nova gramática social, uma nova forma de relação entre Estado e sociedade.

Os movimentos sociais estariam inseridos em movimentos pela ampliação do político, pela transformação de práticas dominantes, pelo aumento da cidadania e pela inserção na política de atores sociais excluídos [...] O que a democratização fez foi, ao inserir novos atores na cena política, instaurar uma disputa pelo significado da democracia e pela constituição de uma nova gramática social. (SOUSA SANTOS; AVRITZER, 2002, p. 54)

Dessa forma, o aumento por si só de participação não significa necessariamente emancipação, pois é preciso adequar essa participação à tentativa de recriação das formas do político: "um espaço público real porque construído universalmente, portanto aquele no qual a crítica e o dissenso organizado dos excluídos pode se instalar na demanda de direitos" (PAOLI, 2002, p. 403). É preciso concretizar o direito de participar na pluralidade das demandas de cidadania.

O Supremo tem uma missão a qual está acima da repercussão do litígio, geralmente limitada às partes, pois questões constitucionais implicam em reflexo além do exclusivo interesse dos litigantes, já que se discute o direito fundamental da própria Nação. A solução da questão levada ao STF tem importância para o público. 
Assim, do ponto de vista procedimental, o balanço é favorável ao desempenho do STF, mas na perspectiva substancial da democracia constitucional, da representatividade cidadã, o instituto do amicus curiae permitiu um redirecionamento da temática com vistas a retomar o debate sobre a própria identidade do Supremo: última instância recursal ou Tribunal Constitucional strictu sensu?

O controle de constitucionalidade pode ser um importante mecanismo emancipatório e de concretização constitucional, na medida em que se constitui em um canal alternativo para aqueles fora do poder. É possível refletir sobre a atuação dos tribunais a partir da categoria comunitarista, quando o Tribunal é provocado a atuar em nome de interesses não estatais, interesses inerentes ao exercício da cidadania. Tratase de associar o comunitarismo com a ideia de democracia participativa. Os tribunais, desde que não estejam demasiadamente preocupados em evitar a confrontação com o poder político, podem expressar valores fundamentais para a democracia.

Portanto, a pergunta está atrelada a uma crise de identidade inerente ao Supremo desde o seu novo desenho por ocasião da Constituição de 1988. Com o advento das comemorações pelos vinte anos da promulgação do texto constitucional e diante de uma nova composição do Tribunal, torna-se salutar retomar questões que possam responder a essa pergunta, solucionando a crise de identidade a partir dos próprios princípios e valores previstos no texto constitucional de 1988. Podemos, com o instituto do amicus curiae, vislumbrar um resgate do novo sentido atribuído pelo texto constitucional de 1988 à cidadania como atitude? A proposta apresentada no presente artigo busca justamente responder positivamente a pergunta, traçando um resgate de instrumentos que aproximem o Supremo de um Tribunal Constitucional strictu sensu, e dessa forma se identificando mais com os preceitos de cunho comunitarista da Constituição de 1988 e resolvendo a apontada crise de identidade.

: ARTIGO APROVADO (24/11/2008) : RECEBIDO EM 30/07/2008

NOTAS

1 Em trabalho sobre a cidadania brasileira, José Murilo de Carvalho (2002) aponta que um dos grandes problemas da liberdade dos modernos é o da viabilização da virtude republicana, que comporta o ativismo político e a preocupação com o bem coletivo. Isso porque esta virtude é típica do mundo antigo e dificilmente é compreensível em sociedades de mercado, “onde nem há tempo disponível para a ação cívica, nem motivação para que as pessoas se desviem da busca do interesse individual. A única justificativa lógica do bem coletivo no mundo utilitário permanece sendo a que o identifica com a soma dos interesses pessoais" (p. 121). A presente análise versará sobre a dinâmica que a justificativa lógica apresentada pelo autor acarreta quando da análise da atuação do Supremo com a promulgação da Constituição de 1988. 
2 Este debate é creditado a Benjamin Constant em Sobre a Liberdade dos antigos comparada com a dos modernos (1819), em que contrapôs a liberdade dos indivíduos em relação ao Estado (liberdade de) à liberdade dos indivíduos no Estado (liberdade em). A primeira forma de liberdade seria característica dos modernos (sociedades comerciais e industriais contemporâneas, marcadas pela intensa divisão do trabalho e pela prevalência dos interesses individuais), e os indivíduos poderiam desenvolver suas potencialidades desde que libertos do poder absoluto do Estado. A liberdade em seria característica dos antigos, ou seja, dos antigos gregos e romanos, em que os indivíduos podiam participar em tempo integral dos corpos de decisão política. Na disputa entre os antigos e os modernos, Benjamin Constant, defensor do liberalismo, conferia um sentido claramente positivo aos modernos.

3 No século XX, outro defensor do liberalismo político, Isaiah Berlin (2002), adaptou a terminologia constantiana para liberdade negativa (liberdade de ou liberdade para) e liberdade positiva (liberdade em). Para o autor o cerne do debate está na questão da obediência e da coerção. "Por que devo (ou alguém deve) obedecer a outro alguém? [...] Com base nas respostas à pergunta dos limites permissíveis de coação, visões opostas são defendidas no mundo atual” (p. 228).

4 Oportuno destacar, entretanto, que sobre o tema específico do controle de constitucionalidade, os comunitaristas o analisam como uma limitação ao processo deliberativo democrático, pois viola "o exercício da autonomia por parte de determinados grupos culturais” (CITTADINO, 2000, p. 194). Como nossa ênfase é a participação política, e não a legitimidade democrática dos Tribunais Constitucionais, não adentraremos este debate aqui.

5 Dois eixos analíticos podem ser apontados quando da análise sobre a posição estratégica do poder judiciário nas democracias contemporâneas: eixo procedimentalista, representado por J. Habermas e A. Garapon, que veem na invasão da política pelo direito uma perda da liberdade e consequente privatização da cidadania; e o eixo substancialista, associado às obras de M. Cappelletti e R. Dworkin, que afirmam que as novas relações entre direito e política seriam tomadas como inevitáveis e favoráveis ao enriquecimento da agenda igualitária, sem prejuízo da liberdade (OLIVERIA; CARVALHO, 2002, p. 13-4). Os autores não lidam diretamente com a judicialização, mas trabalham com temas que norteiam esse fenômeno.

6 Em uma abordagem que defende a adaptação do juiz a uma democracia mais associativa, participativa e mais deliberativa, Garapon (1992) deposita uma grande responsabilidade no exercício das atribuições jurisdicionais: “O prestígio contemporâneo do juiz procede menos de uma escolha deliberada do que de uma reação de defesa em face de um quádruplo desabamento: político, simbólico, psíquico e normativo. [...] O juiz surge como um recurso contra a implosão das sociedades democráticas que não conseguem administrar de outra forma a complexidade e a diversificação que elas mesmas geraram. [...] Os juízes são os últimos a preencher uma função de autoridade”(p. 26-7).

7 "De algum modo o empolamento da polêmica judicialização da política versus politização da justiça, quanto ao papel real desempenhado pelos tribunais de justiça constitucional no processo político de concretização e realização da constituição - bem vistas as coisas, ao cabo e ao resto, um problema de legitimidade -, representa, a um tempo, tanto um momento de viragem do discurso constitucional, no sentido da sua renovação como ciência, quanto um ponto de encontro e de (re)dimensionamento dos domínios jurídico e político" (QUEIROZ, 1990, p. 22).

8 O destaque à abordagem brasileira se dá pela diferença com a abordagem dada por Tate e Vallinder (1995) quando das primeiras análises sobre o "fenômeno": os autores buscaram descobrir nas condições políticas alguns dos motivos da judicialização e, a partir de estudo de casos, desenvolveram oito condições para o processo: democracia, separação dos poderes, política centrada nos direitos, o uso dos tribunais por grupos de interesse, o uso dos Tribunais pela oposição, inefetividade das instituições majoritárias, percepções por parte do público das instituições responsáveis pela elaboração de políticas públicas, proposital delegação da decisão de determinadas controvérsias pelas instituições majoritárias. Institucionalistas, os autores caracterizam a judicialização pela difusão de procedimentos judiciais em arenas de deliberação política, propondo que o ajuizamento de ações que envolvam questões políticas por si só já caracterizaria o fenômeno. "No entanto, os estudos sobre esta temática têm demonstrado que o aumento da litigância na arena política pode ser ocasionado por mecanismos institucionais, os mais diversos, ou por uma alteração no modo de interpretar dos juízes (ativismo judicial). Portanto, as causa da emergência da judicialização a lógicas peculiares, variando de país para país" (OLIVEIRA; CARVALHO, 2002, p. 18).

9 Débora Maciel e Andrei Koerner (2002) criticam a utilização da expressão, alegando que o tema das relações entre judiciário e política na democracia brasileira deve ser estudado sem o recurso ao "conceito pouco preciso, mas de rápida circulação pública, de judicialização da política” (p. 131). É preciso avaliar o papel das instituições judiciais no conjunto de transformações do Estado brasileiro nas duas últimas décadas, centrando a atenção no path histórico desse conjunto, assim como na dinâmica organizacional das diversas burocracias que compõem o sistema judicial. 
10 ADI no 894-3DF, Relator ministro Néri da Silveira, D. J. de 30.11.93, p. 25.981.

11 O momento é oportuno para destacar que o presente trabalho não tratará de questões de cunho processual, como os mencionados dados sobre o número de Agravos e Recursos Extraordinários, e o seu cabimento. Nossa intenção é apenas ilustrar, por intermédio da análise reflexiva dos números apontados, o nosso raciocínio de cunho filosófico, sem se ater a filigranas processuais.

12 A título de ilustração: em 2007, do total de 112.938 processos distribuídos, 56.909 eram Agravos de Instrumento, e 49.708, Recursos Extraordinários, o que representa um total de 106.617 processos, percentual de 94,4\% do total de processos distribuídos, segundo dados extraídos do Portal de Informações Gerenciais do STF.

13 Voto ministro Sepúlveda Pertence, ADI nº 271, p. 154.

\section{REFERÊNCIAS BIBLIOGRÁFICAS}

BARROSO, Luís Roberto. O Controle de Constitucionalidade no Direito Brasileiro. 2. ed. São Paulo: Saraiva, 2006. . Dez Anos da Constituição de 1988. Revista de Direito Administrativo, Rio de Janeiro, n. 214, 1998.

BERCOVICI, Gilberto. Constituição e Política: uma relação difícil. Lua Nova, n. 61, p. 5-24, 2004. . A Constituição Dirigente a Crise da Teoria da Constituição. In: BERCOVICI, Gilberto et al. (Orgs.). Teoria da constituição - estudos sobre o lugar da política no direito constitucional. Rio de Janeiro: Lúmen Júris, 2003. p. $75-150$

. A problemática da constituição dirigente: algumas considerações sobre o caso brasileiro. Revista de Informação Legislativa, Brasília, a. 36, n. 142, p. 35-51, abr/jun 1999.

BERGER, Peter. On the obsolenscence of the concept of honor. In: HAUERWAS, Stanley; MACINTYRE, Alasdair (Orgs.). Revisions: Changing Perspectives in Moral Philosophy. Indiana: University of Notre Dame Press, 1983. p. 172-81.

BERLIN, Isaiah. Liberdade Política e Pluralismo. In: BERLIN, Isaiah. Estudos sobre a humanidade. São Paulo: Companhia das Letras, 2002. p. 226-72.

BERTEN, André. Republicanismo e motivação política. In: MERLE, Jean-Christophe; MOREIRA, Luiz (Orgs.). Direito e Legitimidade. São Paulo: Landy, 2003. p. 21-36.

BUENO, José Antônio Pimenta. Direito Público Brasileiro e a análise da Constituição do Império. Brasília: Senado Federal, 1978.

CANOTILHO, José Joaquim Gomes. Constituição Dirigente e vinculação do legislador. Coimbra: Coimbra, 2001. CAPPELLETTI, Mauro. O controle judicial de constitucionalidade das leis no direito comparado. Porto Alegre: Fabris, 1984. CARDOSO DE OLIVEIRA, Luis Roberto. Direitos republicanos, identidades coletivas e esfera pública no Brasil e no Quebec. n. 304. Brasília: Universidade de Brasília, 2001. (Série Antropologia).

Entre o justo e o solidário: os dilemas dos direitos de cidadania no Brasil e nos EUA. n. 185. Brasília:

Universidade de Brasília, 1995. (Série Antropologia).

. Direitos humanos e cidadania no Brasil: algumas reflexões preliminares. n. 122. Brasília: Universidade de Brasília, 1992. (Série Antropologia).

CARVALHO, Ernani Rodrigues. A judicialização da política no Brasil: apontamentos para uma nova abordagem.

Em ENCONTRO DA ASSOCIAÇÃO BRASILEIRA DE CIÊNCIA POLÍTICA (ABCP), 4., 2004, Rio de Janeiro. Trabalho apresentado... Rio de Janeiro, 2004.

CARVAlHO, José Murilo. Cidadania no Brasil: o longo caminho. 5. ed. Rio de Janeiro: Civilização Brasileira, 2004. CASTRO, Flávia de Almeida Viveiros de. O papel político do Poder Judiciário. Revista de Direito Constitucional e Internacional, n. 38, p. 289-303.

CITTADINO, Gisele. Pluralismo, Direito e Justiça Distributiva - Elementos da Filosofia Constitucional Contemporânea. Rio de Janeiro: Lúmen Júris, 2000.

Poder Judiciário, ativismo judicial e democracia. Em ENCONTRO DA ASSOCIAÇÃO NACIONAL DE PÓS-GRADUAÇÃO E PESQUISA EM CIÊNCIAS SOCIAIS (ANPOCS), 25, 2001, Caxambu. Seminário... Caxambu, 2001.

COELHO, Inocêncio Mártires. As ideias de Peter Häberle e a abertura da interpretação constitucional no Direito brasileiro. Revista de Direito Administrativo, n. 211, 1997. 
DALLARI, Dalmo de Abreu. O Poder dos Juízes. São Paulo: Saraiva, 1996.

GARAPON, Antoine. O juiz e a democracia: o guardião de promessas. 2. ed. Rio de Janeiro: Revan, 2001.

GALANTER, Marc. Direito em Abundância: a atividade legislativa no Atlântico Norte. Revista Crítica de Ciências Sociais, n. 36, p. 103-45, fev. 1993.

HÄBERLE, Peter. Hermenêutica Constitucional - A sociedade aberta dos intérpretes da Constituição: contribuição para a interpretação pluralista e "procedimental” da Constituição. Porto Alegre, Sérvio Antonio Fabris, 1997.

HABERMAS, Jürgen. Direito e Democracia: entre facticidade e validade, v. 2. Rio de Janeiro: Tempo Brasileiro, 1997. HESSE, Konrad. Constitución y Derecho Constitucional. In: BENDA, Ernst et al. Manual de Derecho Constitucional. Madrid: Marcial Pons Ediciones Jurídicas y Sociales, 1996, p. 1-15.

LOIS, Cecilia Caballero. Da União social à comunidade liberal: o liberalismo político de John Rawls e o republicanismo cívico liberal de Ronald Dworkin. In: LOIS, Cecilia Caballero (Org.). Justiça e Democracia: entre o universalismo e o comunitarismo. São Paulo: Landy, 2005. p. 23-49.

MACIEL, Débora Alves; KOERNER, Andrei. Sentidos da Judicialização da Política: duas análises. Lua Nova, n. 57, p. 113-33, 2002.

MACINTYRE, Alasdair. After Virtue: a Study in Moral Theory. Notre Dame, Indiana: University of Notre Dame, 1984. MANCUSO, Rodolfo de Camargo. Recurso Extraordinário e Recurso Especial. 5. ed. São Paulo: Revista dos Tribunais, 1998.

MENDES, Gilmar Ferreira. Controle de Constitucionalidade: aspectos jurídicos e políticos. São Paulo: Saraiva, 1990. OLIVEIRA, Vanessa Elias de. Judiciário e Privatizações no Brasil: existe uma judicialização da política? Dados Revista de Ciências Sociais, Rio de Janeiro, n. 3, v. 48, p. 559-87, 2005.

CARVALHO, Ernani. A judicialização da política: um tema em aberto. Em ENCONTRO DA ASSOCIAÇÃO NACIONAL DE PÓS-GRADUAÇÃO E PESQUISA EM CIÊNCIAS SOCIAIS (ANPOCS), Grupo de Trabalho Controles Democráticos e Cidadania, 2002, Caxambu. Paper... Caxambu, 2002.

PAOLI, Maria Célia. Empresas e responsabilidade social: os enredamentos da cidadania no Brasil. In: SOUSA SANTOS, Boaventura (Org.) Democratizar a Democracia - os caminhos da democracia participativa, v. 1. Rio de Janeiro: Civilização Brasileira, 2002, p. 373-418.

QUEIROZ, Cristina. Os actos politicos no Estado de Direito - o problema do controle jurídico do poder. Coimbra: Almedina, 1990.

Coimbra, 2000 Interpretação Constitucional e Poder Judicial - sobre a epistemologia da construção constitucional. Coimbra:

RAWLS, John. Uma Teoria da Justiça. São Paulo: Martins Fontes, 1997. O Liberalismo Político. São Paulo: Ática, 2000.

SCHMIDT, Ernani Santos. Pensamento comunitário contemporâneo: expressões para um referencial teórico no estudo do direito. Disponível em: <http://www.conpedi.org/manaus/arquivos/Anais/Ernani\%20Santos\%20Schmidt.pdf>. Acesso em janeiro 2007.

SOUSA, Marcelo Alvares de. Cidadania, igualdade e solidariedade: e o Brasil com isso? Dissertação (Mestrado) Departamento de Sociologia, Universidade de Brasília, Brasília, 1999.

SOUZA, Márcia Teixeira de. O processo decisório na Constituição de 1988: práticas institucionais. Lua Nova, n. 58, p. 37-60, 2003.

SOUSA SANTOS, Boaventura. Introdução Geral à Coleção. In: SOUSA SANTOS, Boaventura (Org.).

Democratizar a Democracia - os caminhos da democracia participativa, v. 1. Rio de Janeiro: Civilização Brasileira, 2002, p. 13-27.

; AVRITZER, Leonardo. Para ampliar o cânone democrático. In: SOUSA SANTOS, Boaventura (Org.). Democratizar a Democracia - os caminhos da democracia participativa, v. 1. Rio de Janeiro: Civilização Brasileira, 2002, p. 39-82.

Poderá o direito ser emancipatório? Revista Crítica de Ciências Sociais, Coimbra, 65, p. 3-76, mai. 2003.

TATE, Neal; VALLINDER, Torbjörn. The Global Expansion of Judicial Power. Nova York: New York University Press, 1995.

TAVARES, Ana Lucia de Lima. A Constituição Brasileira de 1988: subsídios para os comparatistas. Revista de Informação Legislativa, Brasília, a. 28, n. 109, p. 71-108, jan./mar. 1991.

TAVARES, Quintino Lopes Castro. Multiculturalismo. In: LOIS, Cecilia Caballero (Org). Justiça e Democracia: entre o universalismo e o comunitarismo. São Paulo: Landy, 2005, p. 89-123.

TAYLOR, Charles. Argumentos Filosóficos. Trad. Adail Ubirajara Sobral. São Paulo: Edições Loyola, 2000.

VELOSO, Zeno. Controle Jurisdicional de Constitucionalidade. Belém: Cejup, 1999.

VIANNA, Luiz Werneck et al. A judicialização da política e das relações sociais no Brasil. Rio de Janeiro: Revan, 1999. (Org). A democracia e os três poderes no Brasil. Belo Horizonte: UFMG, 2002.

VIEIRA, Oscar Vilhena. Supremo Tribunal Federal - Jurisprudência Política. São Paulo: Revista dos Tribunais, 1994. 
Império da lei ou da corte? Revista USP, Dossiê Judiciário, São Paulo, n. 21, p. 70-7, mar./abr./mai. 1994.

WALZER, Michael. The communitarian critique of liberalism. Political Theory, v. 18, n. 1, fev. 1990.

. Esferas da Justiça: uma defesa do pluralismo e da igualdade. São Paulo: Martins Fontes, 2003.

\section{Julia Maurmann Ximenes}

SQN 210, Bloco G, apt. 501

Asa Norte - 70762-070

Brasília - DF - Brasil

juliaximeneslaidp.edu.br
Doutora em Sociologia Política pela Universidade de BRASÍLIA (UNB)

Professora NA ESPECIALIZAÇ̃̃o E NO MESTRADO dO INSTITUTO BRAsiliense de DireIto Público (IDP) 